Research Article

\title{
Analysis of the Acoustic Environment of Typical Residential Areas along a Light Rail Line Based on GIS
}

\author{
Yu Zhao $\mathbb{D}^{1,2}$ Qingwei Yang, ${ }^{1}$ and Peiyin Yuan ${ }^{1,3}$ \\ ${ }^{1}$ College of River and Ocean Engineering, Chongqing Jiaotong University, Chongqing 400074, China \\ ${ }^{2}$ College of Architecture and Urban Planning, Chongqing Jiaotong University, Chongqing 400074, China \\ ${ }^{3}$ College of Shipping and Naval Architecture, Chongqing Jiaotong University, Chongqing 400074, China
}

Correspondence should be addressed to Yu Zhao; zhaoyucq@cqjtu.edu.cn

Received 2 November 2019; Revised 6 April 2020; Accepted 15 May 2020; Published 30 July 2020

Academic Editor: Salvatore Grasso

Copyright (c) $2020 \mathrm{Yu}$ Zhao et al. This is an open access article distributed under the Creative Commons Attribution License, which permits unrestricted use, distribution, and reproduction in any medium, provided the original work is properly cited.

\begin{abstract}
The acoustic environment of urban residential areas is closely related to road traffic noise. More specifically, the effect of the light rail on the old residential area in Chongqing is potentially profound. Using geographic information system (GIS) to construct a map of the urban light rail's influence on the acoustic environment of residential areas, the influence of noise can be determined. Very few studies exist on the impact of light rails on the acoustic environment of residential areas, and there is no literature on the impact of light rails on the acoustic environment of residential areas using GIS. In this study, the degree of influence of a light rail on nearby residential areas and the diffusion degree of light rail noise in these areas during various times of the day were analysed by measuring the objective indicators of acoustic landscape elements and evaluating subjective indicators. The layout mode of the residential areas and the light rail were superimposed, and other traffic noise influences were eliminated. This method provides a scientific basis for the planning, design, and reconstruction of residential areas.
\end{abstract}

\section{Introduction}

The World Health Organization (WHO), which advocates the construction of healthy houses (houses that enable residents to be in good physical, mental, and social condition), stipulates that noise in "healthy houses" is less than one decibel $(\mathrm{dB})$. Approximately $40 \%$ of the global population is exposed to road traffic noise over $55 \mathrm{~dB}$ (A) during daylight hours and cannot meet acoustic comfort requirements; $20 \%$ of the population has exposure levels greater than $65 \mathrm{~dB}(\mathrm{~A})$. At night, more than $30 \%$ of the population is exposed to an equivalent sound level greater than $55 \mathrm{~dB}(\mathrm{~A})$, considerably higher than what is considered acceptable by the WHO [1]. Approximately 240 million people in the European Union are strongly dissatisfied with traffic noise, according to a study on noise annoyance [2]. Traffic noise pollution is becoming increasingly serious. Road traffic noise complaints are on the rise and affect the normal order of society [3]. A potential solution to this problem is the instillation of sound barriers in areas that experience large traffic interferences. However, traffic noise complaints remain an issue, and using "traffic noise complaints" as keywords on Google provides more than 800,000 related articles in China alone. In European and American countries, traffic noise has become an important urban issue related to government decision-making and based on noise prediction, management policies have been formulated, and multidepartment cooperation has been adopted to take preventive measures [4].

"Noise instruction" is based on a noise map which is used as a platform to determine the noise status and its prediction at the city scale; this is followed by the compilation of an action plan. In the United States of America, noise prediction results are also used to frame highway implementation plans and solve practical problems to reduce public complaints [5].

The overall acoustic environment of residential areas is formed by a combination of sound elements [6]. The main components of the acoustic environment include natural sound, human sound, artificial sound, traffic noise, and 
other sounds [7]. Currently, there are two types of commonly used evaluation methods of the acoustic environment in residential areas, namely, the subjective and the objective methods [8]. The objective method is based on the national noise level standard. However, when the noise level of the living environment reaches the national standard threshold, residents will typically not feel uncomfortable in their homes; however, this does not necessarily mean that their noise environment will be satisfactory and pleasant. Therefore, the second approach, namely, the subjective evaluation, is required to evaluate the acoustic environment of residential areas. This method is predominately based on the opinions of individuals living in the residential areas. Residents\#x2019;s opinions were obtained through questionnaires, acoustic environment survey reports, and subjective evaluation methods. These results are not limited by data, but based on the subjective feelings of residents to evaluate the acoustic environment. This approach is adopted from a psychological and statistical perspective [9].

As a large-scale quantitative prediction and evaluation technology, noise mapping involves the construction of a data map that represents the level of an acoustic environment in a certain area with different colours. It is generally constructed using Geographic Information Systems (GIS) combined with acoustic simulation model software and verified and corrected by measured data. With the continuous development of urban traffic, noise is gradually transferred from the road to the air. The traditional method of studying traffic noise on the ground does not provide an indication of the traffic noise in the surrounding residential areas. At present, there are two representative studies on the influence of high-priced rail transit on urban acoustic environments in China. These studies model and analyse the acoustic environment and propose effective improvement measures from various aspects [10].

Chongqing was the first city in China to have a straddle monorail and now has several high-priced track lines. The distance between the railway tracks and residential buildings in the city is very close, even within $5 \mathrm{~m}$ of one another, and many residential areas are distributed on both sides of the light rail.

Noise mapping is a method used to predict the acoustic environment in a certain area and includes measured and calculated noise levels. The reliability of the built area can be guaranteed by the verification of the measured and calculated results. In general, this method is suitable for large area noise prediction, but not for residential areas along roads that are most seriously affected by noise. With the development of the city of Chongqing, the traffic noise is becoming increasingly complex.

The Yangjiaping block was considered as the study area (Figure 1). The spatial acoustic environment was studied systematically through interviews with the users of the squares and microclimate measurement campaigns [11]. The Yangjiaping block is predominately residential and also has a shopping mall and a pedestrian street. The specific research area in this block was in the centre of the residential area, surrounded by a light rail line. The surrounding acoustic environment of the residential areas in the block is very

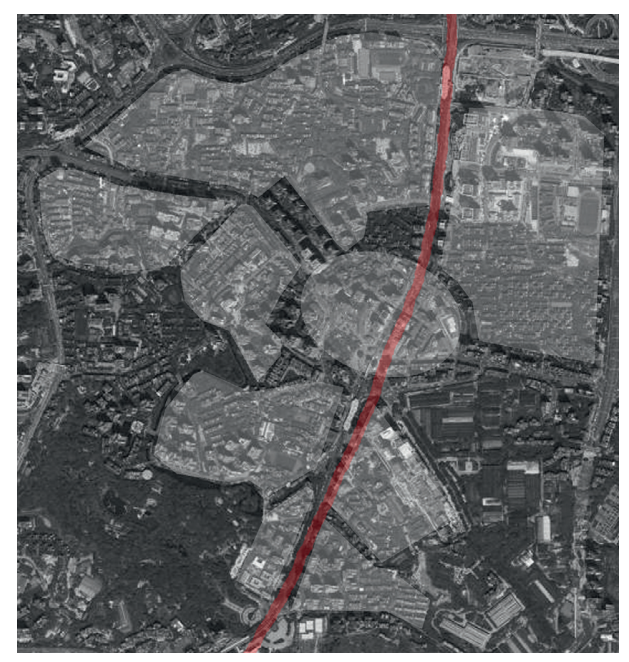

Figure 1: Location of the study area and the distribution of residential areas.

complex, and the impact of light rail noise merits investigation [12].

\section{Methods}

To monitor the acoustic environment of the residential areas under the influence of ground rail transit, measuring points were arranged outdoors in residential areas according to the regulations, and the influence of reflection on the noise value should be reduced to the greatest extent possible during the measurement [13]. The height of the measuring points was $1.2 \mathrm{~m}$ above the ground. Figure 2 shows the layout of the measuring points $\mathrm{A}$ to $\mathrm{X}$. The measuring points were uniformly arranged in the vulnerable area near to the light rail line and then outwardly arranged at certain distances. These sites were located on the open areas of the residential areas to exclude the influence of greening, trees, and buildings on the test results. The measurement time did not consider the different departure frequency of the light rail, but only whether the light rail passes. In the week of May 20 to May 26, Sunday, Monday, Thursday, and Friday were selected to measure the sound level of the residential areas along the light rail using a hand-held sound detector. The selected measurement time was representative, and the residents generally stayed in the residential area. Therefore, the measurement method of short times and multiple times was adopted. The study area was divided into several grids of $10 \mathrm{~m} \times 10 \mathrm{~m}$ and $30 \mathrm{~m} \times 30 \mathrm{~m}$ with the land classification of the study area and the road network skeleton as the base map. The former is used for dividing the residential areas and processing the general data, while the latter is used for other land use and processing observation data. The sound level at 24 monitoring points was collected and recorded in four time periods of 7-8 points, 11-12 points, 17-18 points, and 22-23 points. If there was a sudden fluctuation in the data at a certain point, the data for that area were measured several times, eliminating the effect of one noise each time. The data for the time when the rail passed were measured separately from those when the rail did not pass. 


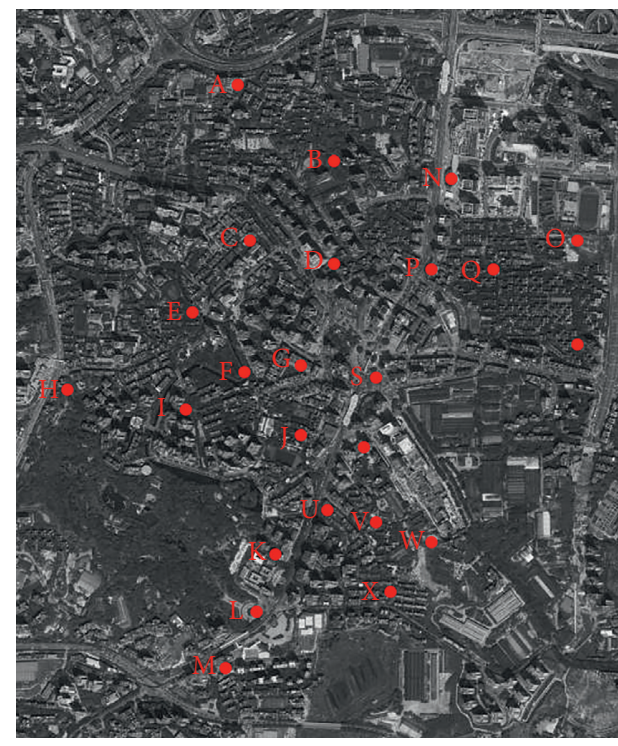

FIGURE 2: Location of the 24 measurement points.

The plan of the research area and the collected sound level data were imported into ArcGis10.2, and the inverse distance weighted interpolation method was used to draw the figure based on the approximate similarity principle. The inverse distance weighted interpolation method is also referred to as the inverse distance multiplication method. The method of inverse distance squares is a weighted average interpolation method, which can be interpolated exactly or smoothly. The quadratic parameter determines whether the weight coefficient will decrease with an increase in the distance from a grid node [14]. The nearest data points of a relatively large power were given a higher weight share, and the weight was distributed evenly to all data points of the smaller power, to achieve the assignment of each point.

Due to the limitations of the environmental conditions, it is impossible to collect data for each point in the region. Therefore, the inverse distance weighted interpolation method was adopted to collect the data for one point in each grid, which was then used to assign values to all the points in the grid, thus forming a complete acoustic environment map.

\section{Sound Level Analysis}

The changes at 7:00 a.m. on each of the observed days were very similar. As expected, the decibel level at 7 a.m. on Monday and Friday was slightly higher than on the other days analysed. The horizontal axis is the point position of the 24 monitoring points, and the vertical axis is the decibel value measured by each monitoring point at 7 a.m. (Figure 3). It can be seen from the broken line graph that the decibel value of most monitoring points changes little at 7 o'clock in the morning on the different days, and only a few points show a significant trend change. At 7 a.m., the noise levels generally fluctuate between 60 and $90 \mathrm{~dB}$, with the main trend being around $70 \mathrm{~dB}$, which is a higher level in the subjective assessment. According to the sound environment

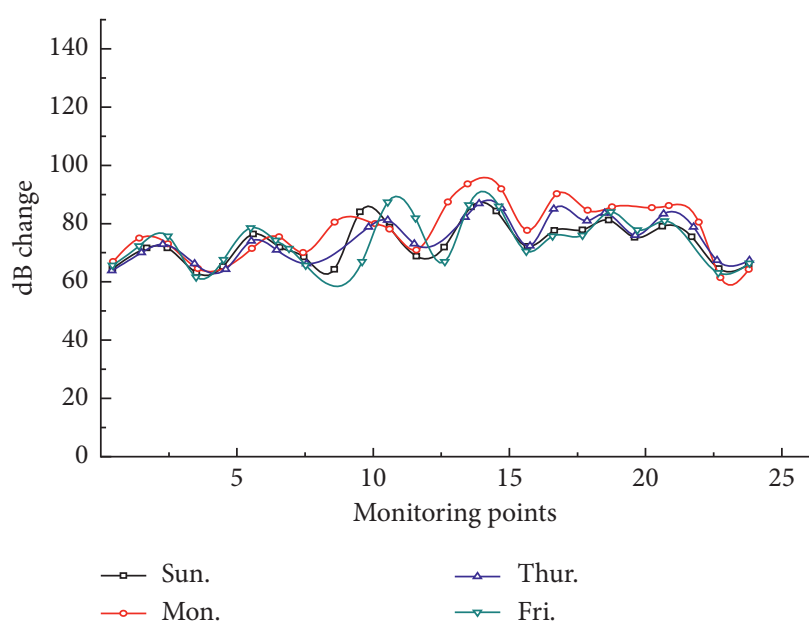

FIgUre 3: Noise levels at 7 a.m. for the 24 measuring points.

assessment standard, the decibel value of each measuring point reached the comfortable standard on Sunday morning, as shown in Figure 3.

According to the investigation results, 12 o'clock represents the peak hour of activity in the area, which has a certain impact on the noise measurement results. The trend was much stronger at 12 p.m. than at 7 a.m., and Sunday and Monday showed the same trend. At 12 p.m. on Thursday, every measurement point was affected by the light rail noise. On Friday, areas closer to the light rail experienced a greater noise impact. The measurement points close to the light rail are less affected by the light rail noise than other areas which experience traffic and social life noises, as shown in Figure 4.

At around 6 p.m., the decibel levels were similar to those at 7 a.m.; the average decibel levels were higher than those at 12 p.m. at the 24 monitoring points. The noise at the measurement point close to the light rail was over $80 \mathrm{~dB}$, seriously impacting the nearby residential buildings. The decibels of the measurement points close to the light rail showed the same trend as the measured values at 7 a.m. Measurements of noise near the light rail stations and pedestrian streets varied significantly, with increased rush hour traffic. The pedestrian streets have higher noise levels, especially on Saturday. The area far away from the main road was less affected by the light rail noise, and the change in sound level was relatively stable, which is consistent with the passing time of the light rail, as shown in Figure 5.

Figure 6 shows the trends in decibel values at 10 p.m. on Sunday, Monday, Thursday, and Friday. The decibel value of each monitoring point was similar for the four-day study period at this time, and the influence of noise on the residential areas along the light rail mainly originates from human activities and traffic. At 10 p.m., the impact of these noise makers was largely minimized. The change in the decibel trend at 10 p.m. was consistent with the light rail passing time.

The average decibel levels were higher at 7 a.m. and 6 p.m. On Thursday, the average decibel level was 77 . Decibel levels at 12 p.m. on Thursday and Friday were the lowest for the study period. Average decibel levels at $12 \mathrm{p} . \mathrm{m}$. on Sunday 


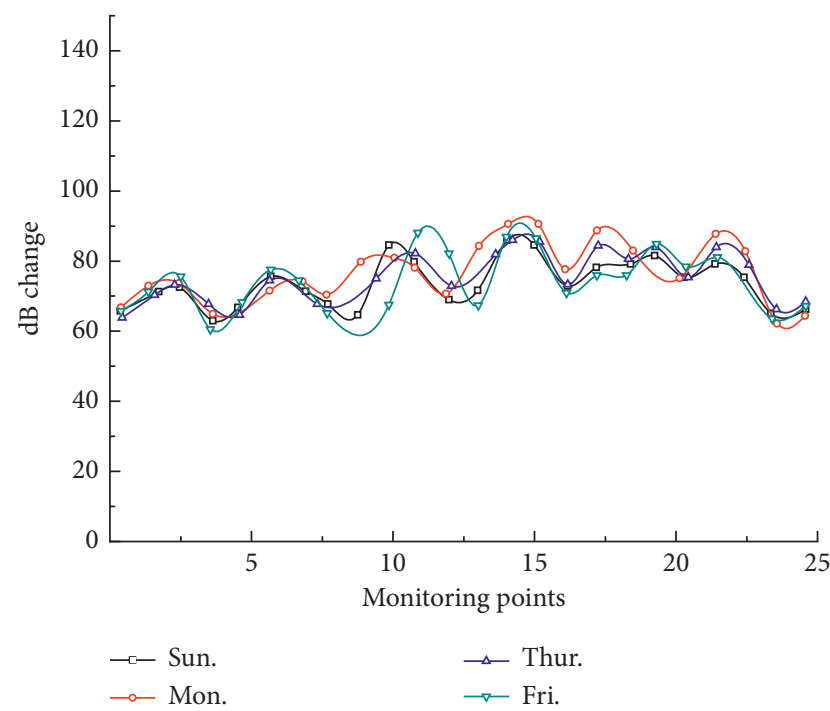

Figure 4: Noise levels at 12 p.m. for the 24 measuring points.

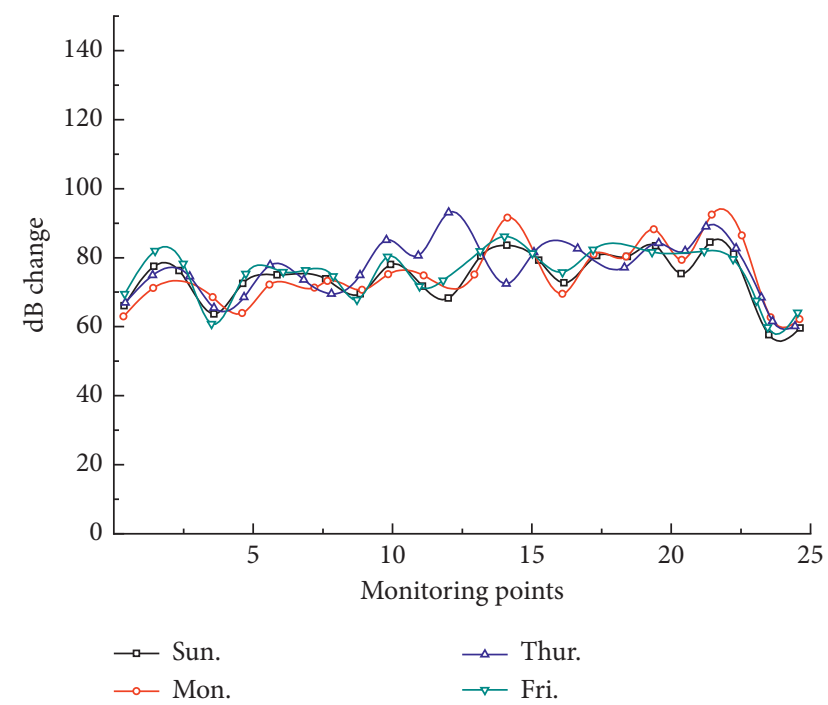

Figure 5: Noise levels at 6 p.m. for the 24 monitoring points.

and Friday showed low values of 38.1 and 45.7, respectively. As per the standard definition of a healthy house with regard to the noise level, noise should be less than 50 decibels [15]. Traffic flow survey results showed that Sunday traffic was not concentrated at a certain time and was generally less than that on other days. The noise at 10 p.m. was relatively low and the decibel level changed steadily.

As shown in Figure 7, the decibel value fluctuates at approximately $75 \mathrm{~dB}$ and experiences a significant change at 12 p.m., with a maximum of $76 \mathrm{~dB}$ and a minimum of $70 \mathrm{~dB}$. The highest decibel period of the day is 6 p.m., with noise recordings in excess of $75 \mathrm{~dB}$. The average decibel recordings at night are the lowest and tend to vary minimally between 68 and $70 \mathrm{~dB}$. According to the standards of environmental noise in urban areas, taking into consideration the actual situation of the current urban environment, the limit of acoustic environmental noise in mixed residential and commercial areas in cities is $60 \mathrm{~dB}$.

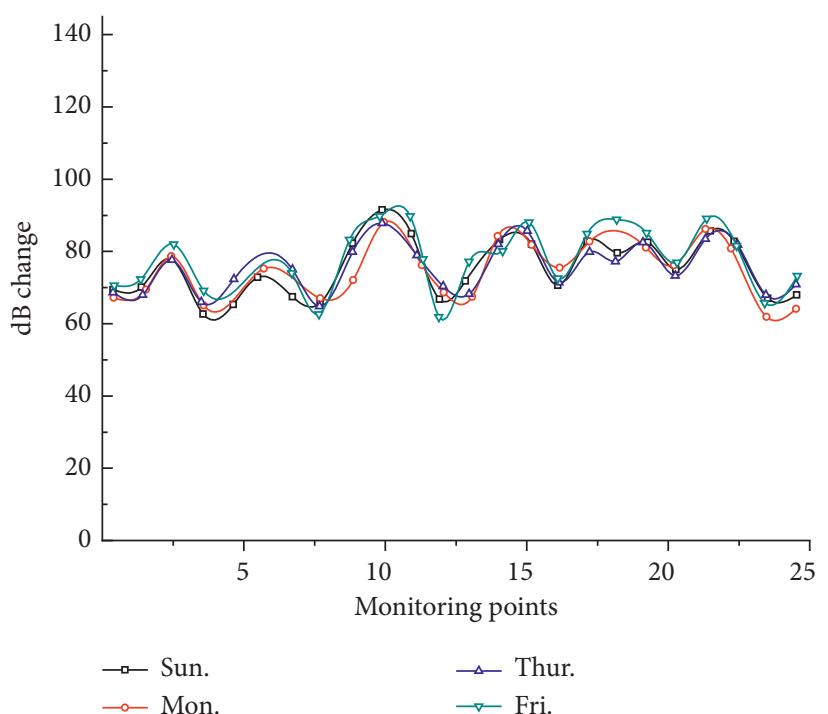

FIgURE 6: Noise levels recorded at 10 p.m. for the 24 monitoring points, with fluctuations corresponding to the passing of the light rail.

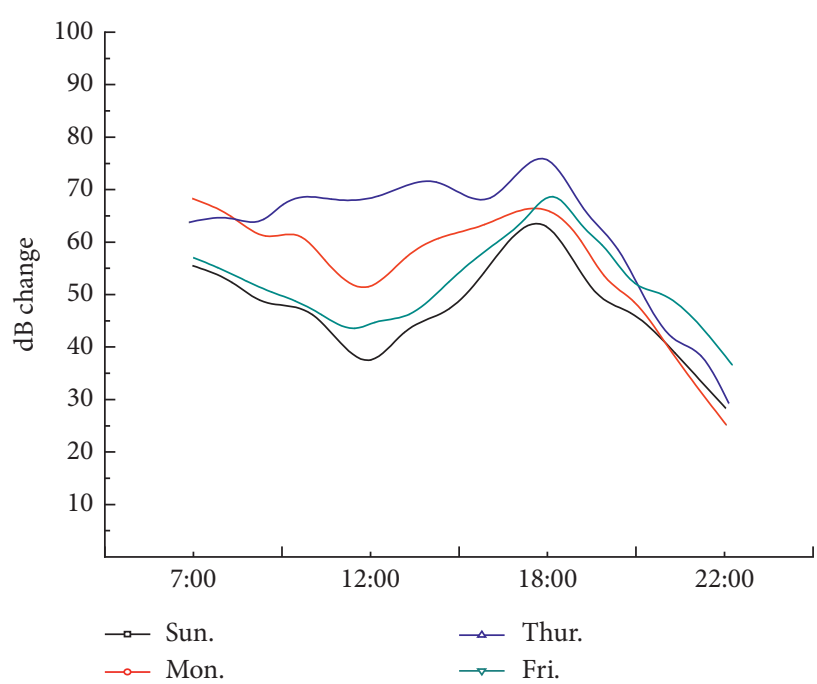

Figure 7: Variation trend in the noise level.

It can be seen from the data analysis that the measured values of the monitoring points differed extensively. Therefore, these points were monitored several times. Residential areas are distributed on both sides of the main road and should meet the fourth category of acoustic environmental standards of no more than $70 \mathrm{~dB}$ during the day and $55 \mathrm{~dB}$ at night. Figure 8 shows that the decibel values in the study area exceeded the standard value. Excessive noise affects residents' wellbeing and can cause a variety of mental diseases [3]. Furthermore, a good acoustic environment equates to a restful environment, which is crucial for the physical comfort and mental sanity of the residents. Therefore, it is of great significance to study the distribution of living acoustic environments.

The main reason for the significant variation in the noise levels between the bus stations and light rail stations is the 


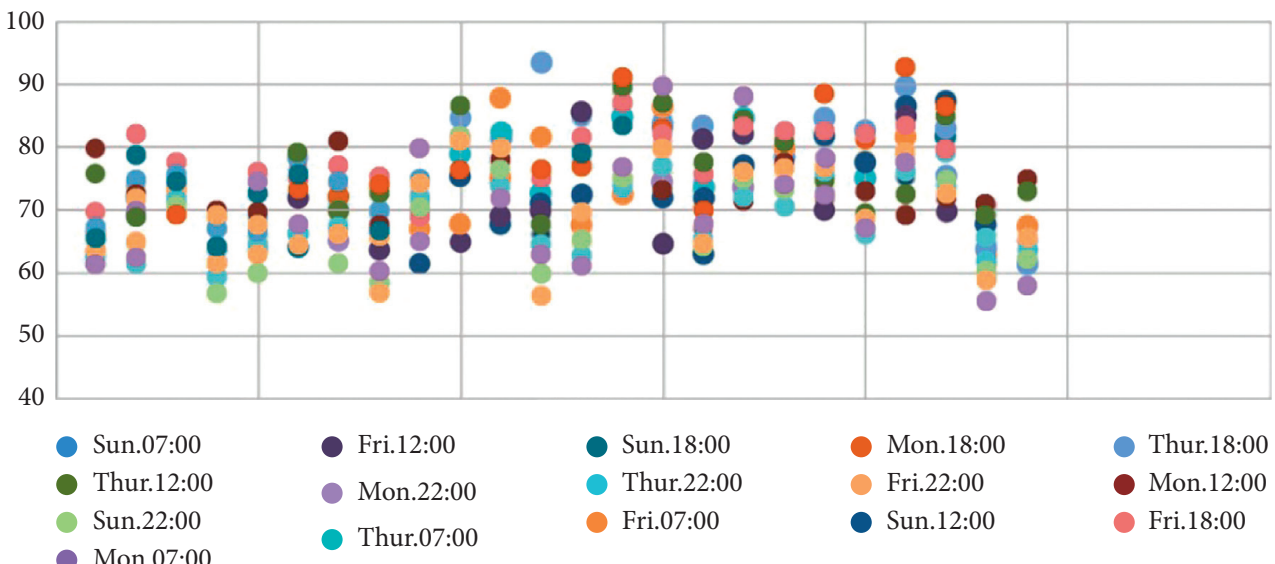

FIGURE 8: dB bitmap.

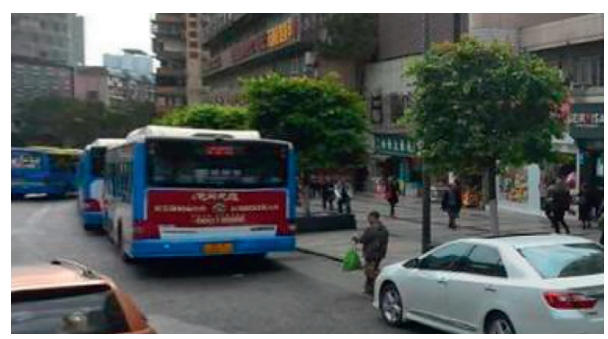

(a)

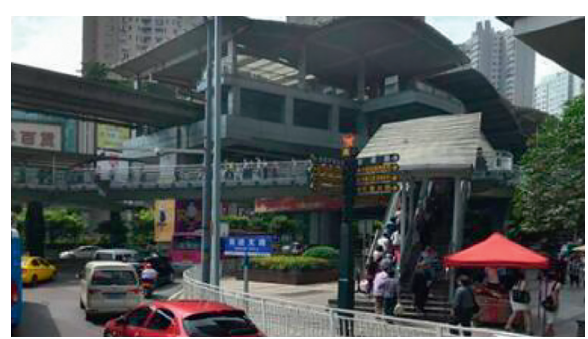

(b)

FiguRE 9: Example of a typical bus station (a) and light rail station (b) where the crowd concentration significantly influences the noise test results.

number of people. As the flow of people increases, the decibel value increases accordingly. Secondly, the presence of shops influences the decibel values of nearby measuring points (Figure 9). In addition, human activities influence the acoustic environment; however they are generally irregular. When human activities change significantly, the acoustic environment of the region also changes [16].

\section{Acoustic Environment Map Analysis}

4.1. Analysis of Acoustic Environment Map in Different Time. The acoustic environmental map was imported into a GIS through field data collection, and the measured values were subsequently imported into the plan of residential areas along the light rail in the study area. Using the inverse distance weighted interpolation, every point in the study area was assigned a value. The acoustic environment map can directly analyse the acoustic environment of typical residential areas along the light rail and indicate the impact of sound on residential areas along the light rail. Simultaneously, through the distribution of main road routes and light rail stations in the plan, the acoustic environment of this area can be analysed under certain conditions, and the acoustic environment of residential areas with different layout patterns can be compared and analysed. The black line in the acoustic environment map is the main route of the main road, the traffic line across the study area represents the light rail line, and the block in the plan is the residential area along the light rail.

At 7 a.m. on Sunday, residential areas near the light rail station and the pedestrian street were significantly affected by the light rail noise, with the transverse influence range exceeding $10 \mathrm{~m}$. Environmental upgrading in areas beyond the maximum impact area met the national standards. The highest decibel value in the study area was 86 , and a large number of residential buildings were located in the vicinity. From a subjective perspective, this part of the residential area undoubtedly experiences serious noise pollution. Weekends are the longest time for residents to stay in the residential area. Moreover, majority of the people are asleep at 7 a.m. A comfortable rest environment is crucial for the wellbeing of the residents, and excessive sound will undoubtedly affect the quality of their rest (Figure 10(a)). Compared to the situation at 7 a.m., the influence range of light rail noise is slightly reduced. In the core area in the Shengli road community, the highest noise level measured was $89 \mathrm{~dB}$ (at the main intersection) and the lowest was $61 \mathrm{~dB}$ (Figure 10(b)). The average decibel value of the study area reached its highest at 6 p.m., where it exceeded $65 \mathrm{~dB}$. It can be seen from the sound environment diagram that the noise extends in the southwest direction along the light rail line, and its influence is gradually reduced $30 \mathrm{~m}$ away from the light rail station. The influence of traffic noise on the acoustic environment of residential areas is much greater than that of 

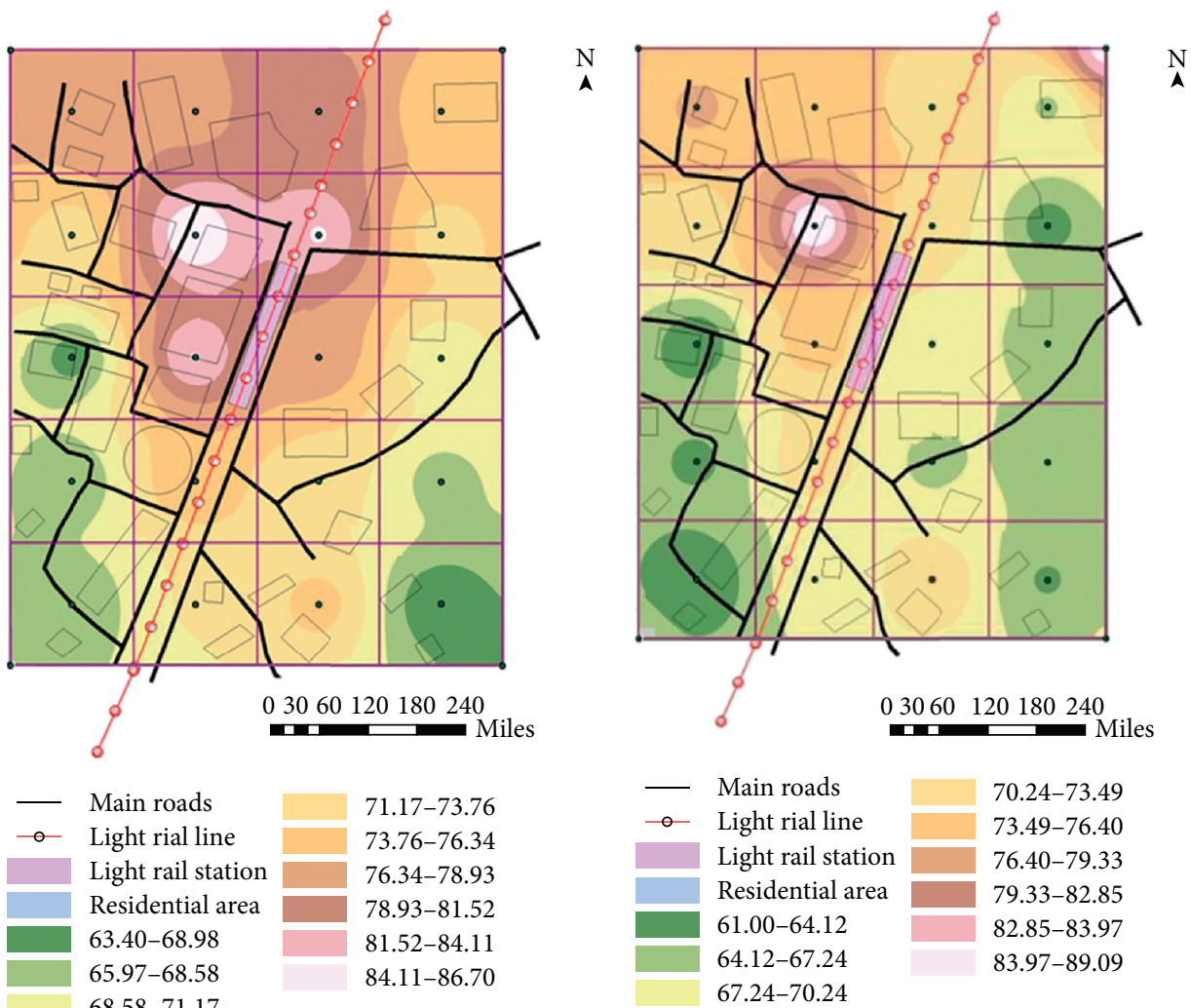

(a)

(b)
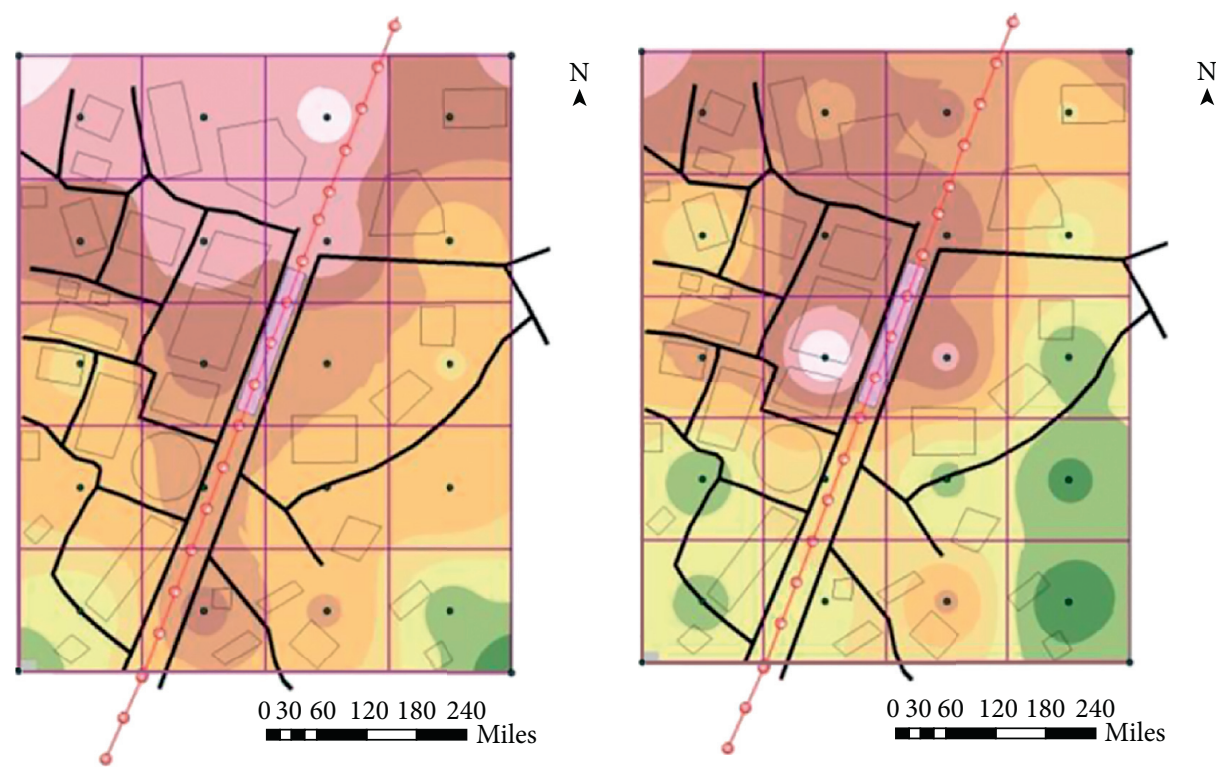

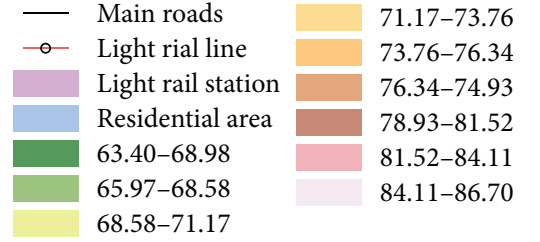

(c)

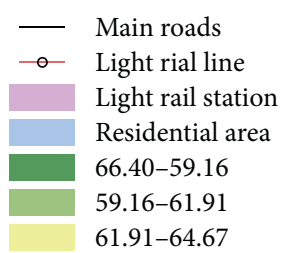

(d)

Figure 10: The acoustic environment for Sunday. (a) 7:00 a.m. (b) 12:00 p.m. (c) 06:00 p.m. (d) 10:00 p.m. 


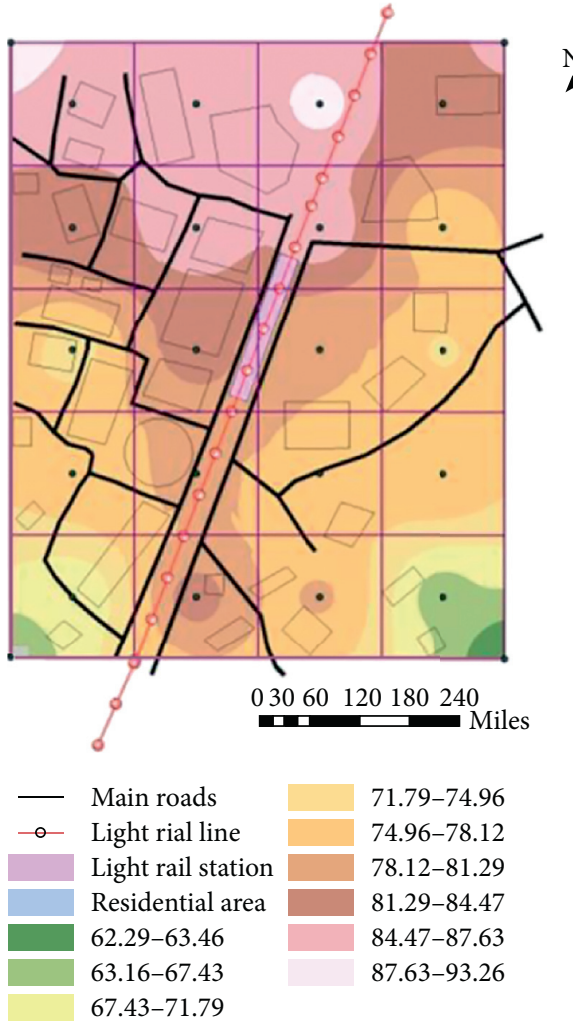

(a)
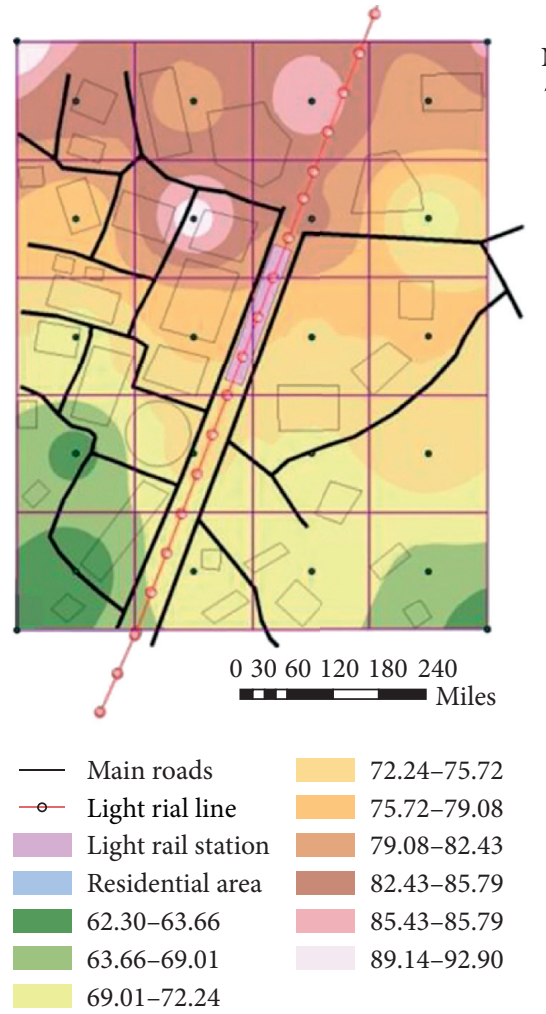

(c)

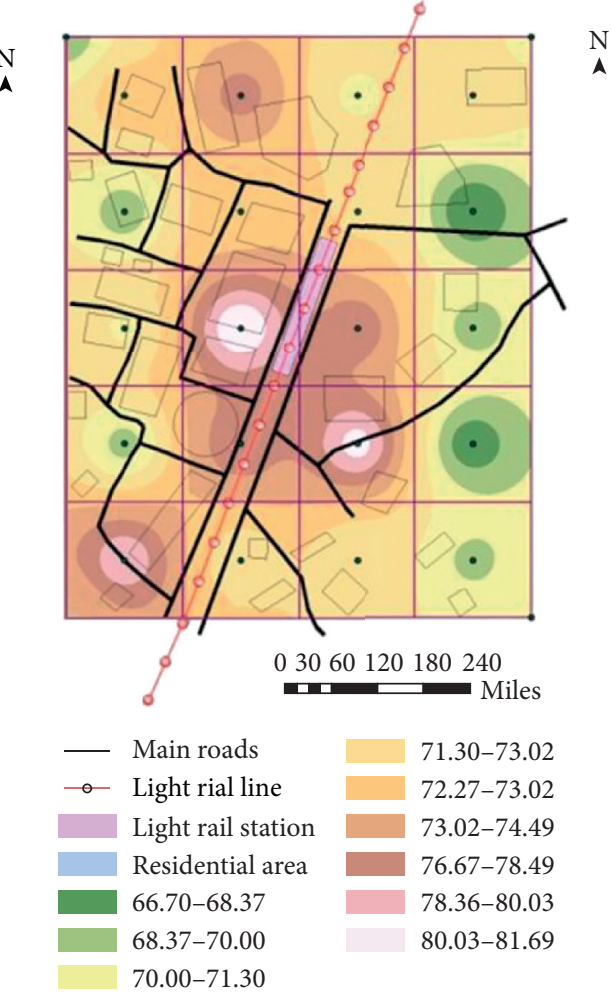

(b)
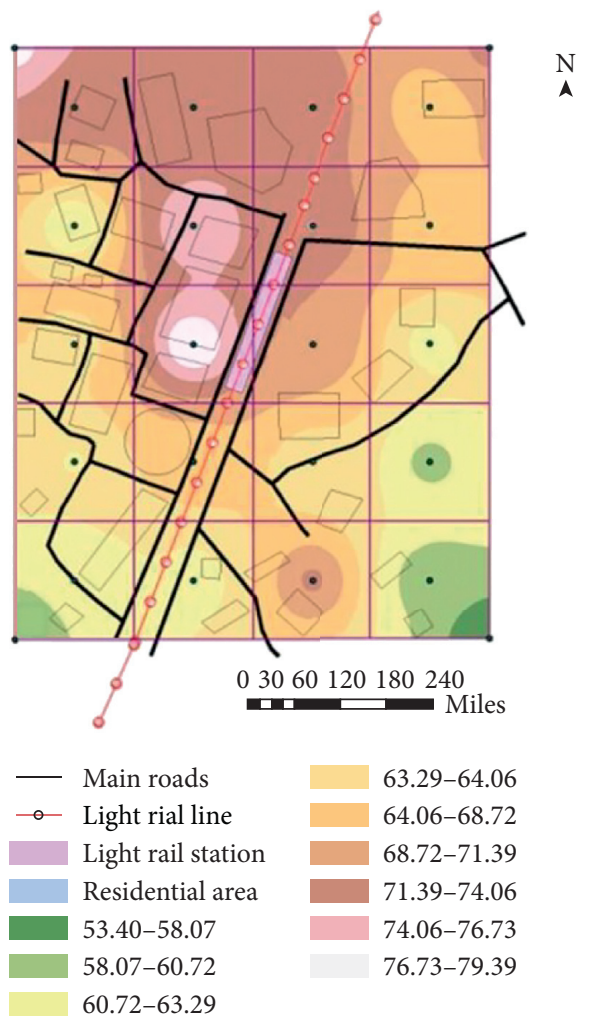

(d)

Figure 11: The acoustic environment for Monday. (a) 7:00 a.m. (b) 12:00 p.m. (c) 06:00 p.m. (d) 10:00 p.m. 


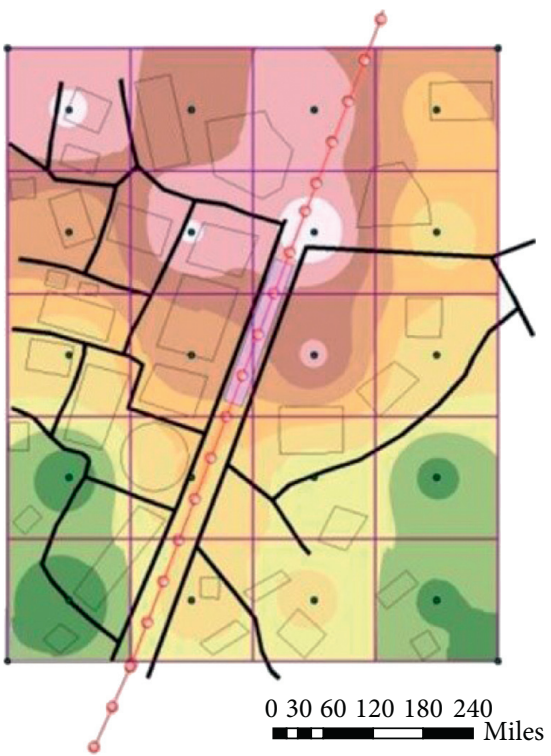

— Main roads

- Light rial line Light rail station Residential area 64.80-67.23 $67.23-69.67$ $69.67-72.10$

(a)
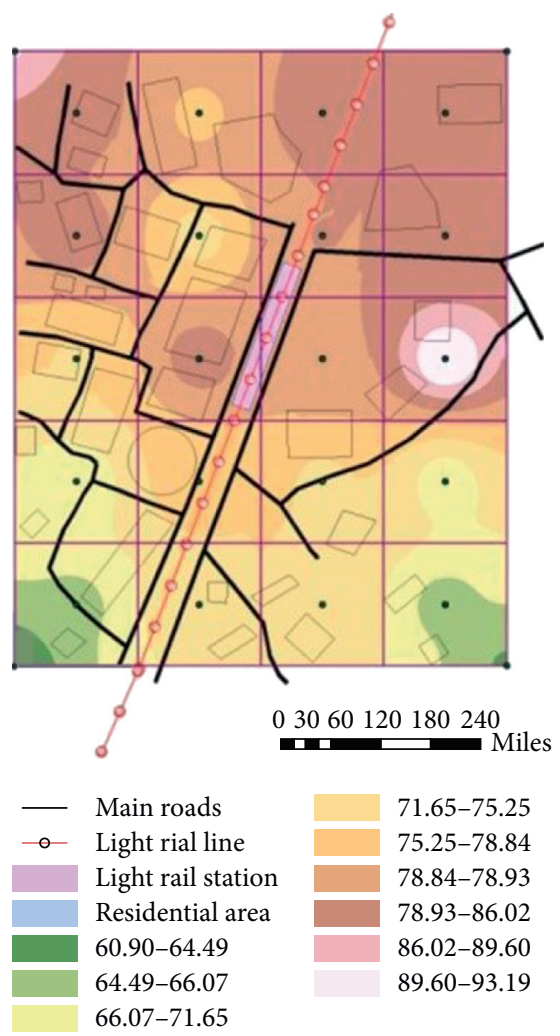

$\mathrm{N}$

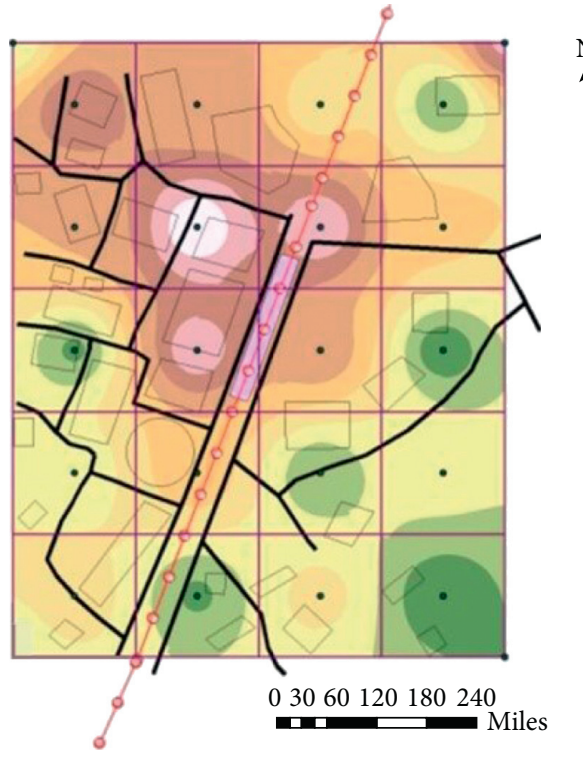

$74.21-76.49$ $76.49-79.20$ $79.20-81.61$ 81.61-84.19 $84.19-86.67$ $86.67-89.20$

(b)

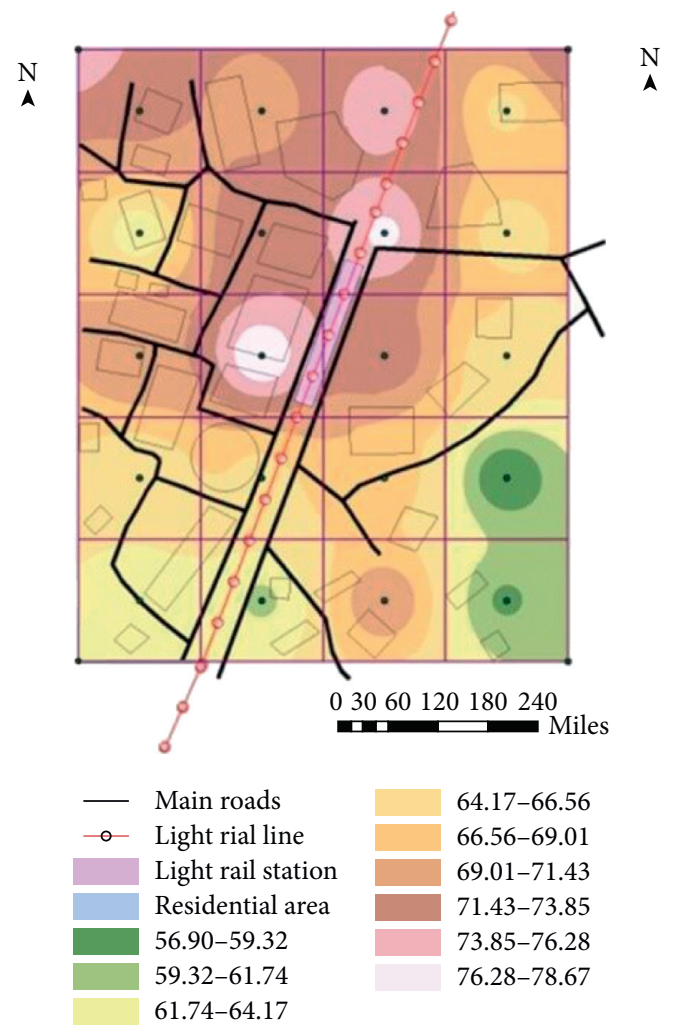

(d)

FIgURE 12: The acoustic environment for Thursday. (a) 7:00 a.m. (b) 12:00 p.m. (c) 06:00 p.m. (d) 10:00 p.m. 

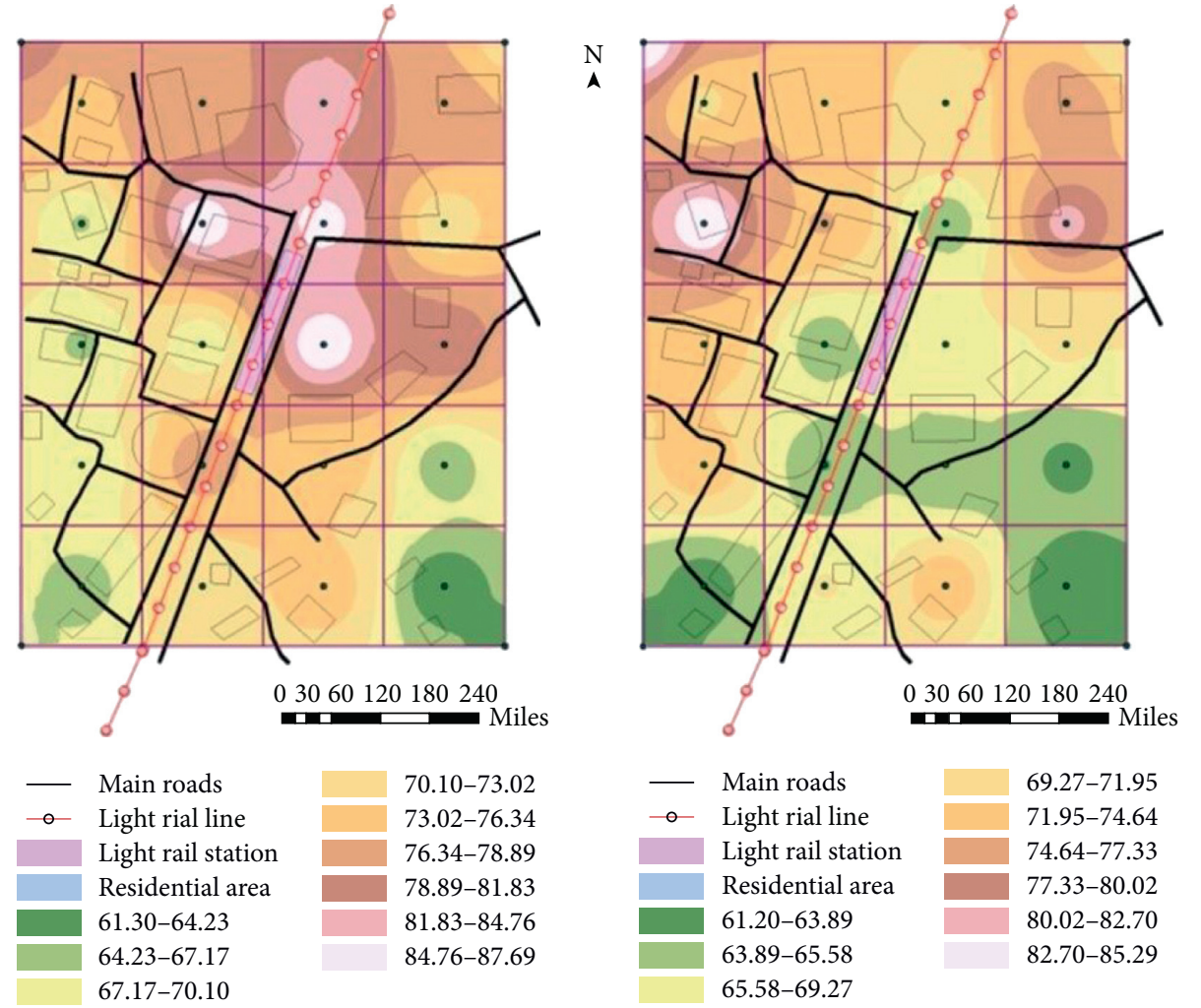

(a)

(b)
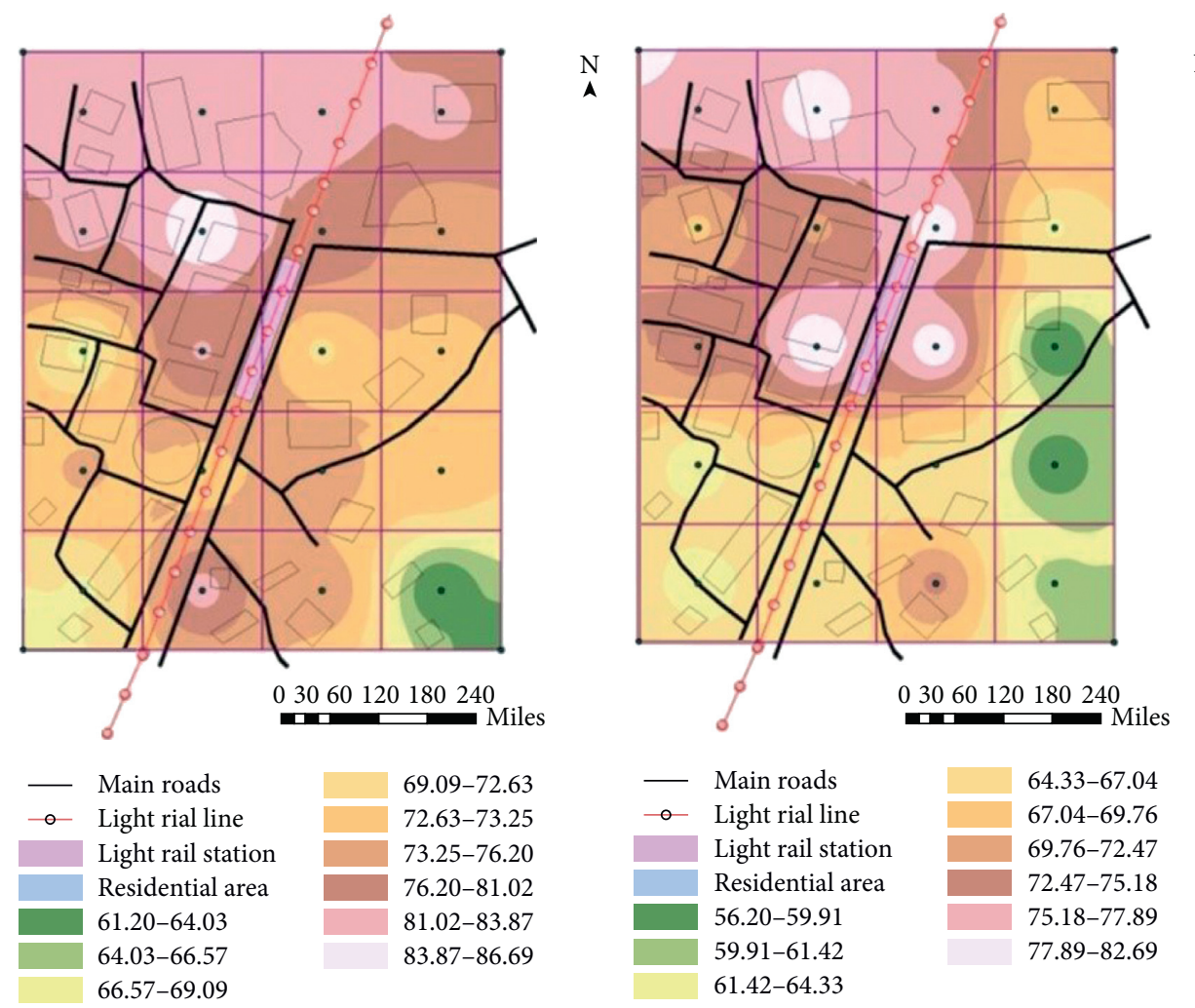

(c)

(d)

FIgURE 13: The acoustic environment for Friday. (a) 7:00 a.m. (b) 12:00 p.m. (c) 06:00 p.m. (d) 10:00 p.m. 
social noise (Figure 10(c)). At 10 p.m., the noise affected area extends to the northwest side. The area with poor sound environment quality is no longer concentrated at the station, but the decibel value of the pedestrian street is still relatively high, at approximately $70 \mathrm{~dB}$. The sound quality of residential areas on the west side of the commercial street was better, with a minimum value of $56 \mathrm{~dB}$ (Figure 10(d)).

At 7:00a.m. on Monday, most residential areas in the study area had poor acoustic environment quality. As shown in Figure 11(a), the impact range of light rail noise covered all residential areas in the northwest. Since the pedestrian flow has not started to increase at this time, the impact of traffic noise was far greater than that of other noise sources, and the average noise value of each residence was above $75 \mathrm{~dB}$. The noise of the light rail was distributed at 12:00 p.m., moving southward, and the impact on the northwest side was no longer severe. The average noise value at this time was $68 \mathrm{~dB}$. However, in the residential areas near to the light rail station, the sound environment quality was still not high, and the noise value of the residential areas on both sides of the station is approximately $76 \mathrm{~dB}$ (Figure 11(b)). During rush hour on Monday, the impact of the pedestrian street on the acoustic environment of the residential areas was greater than that of the light rail station. The acoustic environment quality of the northern side of the study area was relatively poor, measuring a noise value of $85 \mathrm{~dB}$ (Figure 11(c)). At 10 p.m., the west residential area was less affected by the light rail noise. With the expansion of the distance of rail transit lines, the noise value has an obvious tendency to decrease and is positively correlated with the distance. It can be seen from the acoustic environment diagram of this study that the influence factor of the light rail station must be included (Figure 11(d)).

The acoustic environment at 7 a.m. on Thursday shows that the maximum noise value is $86 \mathrm{~dB}$ and the minimum is $63 \mathrm{~dB}$. Although the quality of the acoustic environment for residents living in the west did not meet the standards of comfort, it was relatively less affected by the light rail noise compared to this time on the other days. The area within $60 \mathrm{~m}$ of the light rail was severely affected by noise (Figure 12).

Based on the sound environment map at 7 a.m., the decibel value near the road was higher, about $87 \mathrm{~dB}$, while the noise was only $61 \mathrm{~dB}$ near the light rail station and residential area. At $30 \mathrm{~m}$ away from the light rail station, the noise gradually reduced. In residential areas, it is the decibels range that residents can accept (Figure 13(a)). The acoustic environment map at 12 p.m. on Friday showed that the residential area near the light rail was not affected by noise, and the average value was $70 \mathrm{~dB}$. The light rail was in normal operation on the day of observation, and commercial and social activities did not change. However, compared with the acoustic environment map at other times, the area affected by the light rail was greatly reduced. The traffic noise on the main road decreased significantly (Figure 13(b)). As can be seen from the sound environment map at 6 p.m. on Friday, the decibel value of the residential areas along the light rail was very high, around $75 \mathrm{~dB}$, as a result of the rush hour traffic. On the southeast side of the light rail, the noise
TABLE 1: Daytime average decibel values.

\begin{tabular}{lc}
\hline Monitoring stations & $\mathrm{dB}$ values \\
\hline 1 & 67 \\
2 & 73.0 \\
3 & 74.0 \\
4 & 64.0 \\
5 & 69.0 \\
6 & 75.0 \\
7 & 72.1 \\
8 & 69.2 \\
9 & 70 \\
10 & 78.3 \\
11 & 77.0 \\
12 & 73.0 \\
13 & 77.0 \\
14 & 84.2 \\
15 & 81.1 \\
16 & 73.2 \\
17 & 80.2 \\
18 & 78.8 \\
19 & 79.7 \\
20 & 76.0 \\
21 & 82.0 \\
22 & 79.2 \\
23 & 64.2 \\
24 & 65.9 \\
\hline
\end{tabular}

Table 2: Average decibel values at night.

\begin{tabular}{lc}
\hline Monitoring stations & $\mathrm{dB}$ values \\
\hline 1 & 61.9 \\
2 & 63.1 \\
3 & 71.7 \\
4 & 58.9 \\
5 & 62.5 \\
6 & 66.0 \\
7 & 64.9 \\
8 & 58.0 \\
9 & 70.2 \\
10 & 80.0 \\
11 & 75.3 \\
12 & 60.7 \\
13 & 64.3 \\
14 & 74.3 \\
15 & 76.5 \\
16 & 65.1 \\
17 & 73.8 \\
18 & 74.1 \\
19 & 74.5 \\
20 & 67.1 \\
21 & 77.7 \\
22 & 73.0 \\
23 & 59.0 \\
24 & 62.3 \\
\hline
\end{tabular}

gradually decreased to about $61 \mathrm{~dB}$ in the area $20 \mathrm{~m}$ away from the light rail, reducing to a comfortable level for the sound environment. At this time, light rail noise has a great impact not only on the residential area but also on a primary school situated in the southeast corner (Figure 13(c)). Compared to other times, the map of the sound 


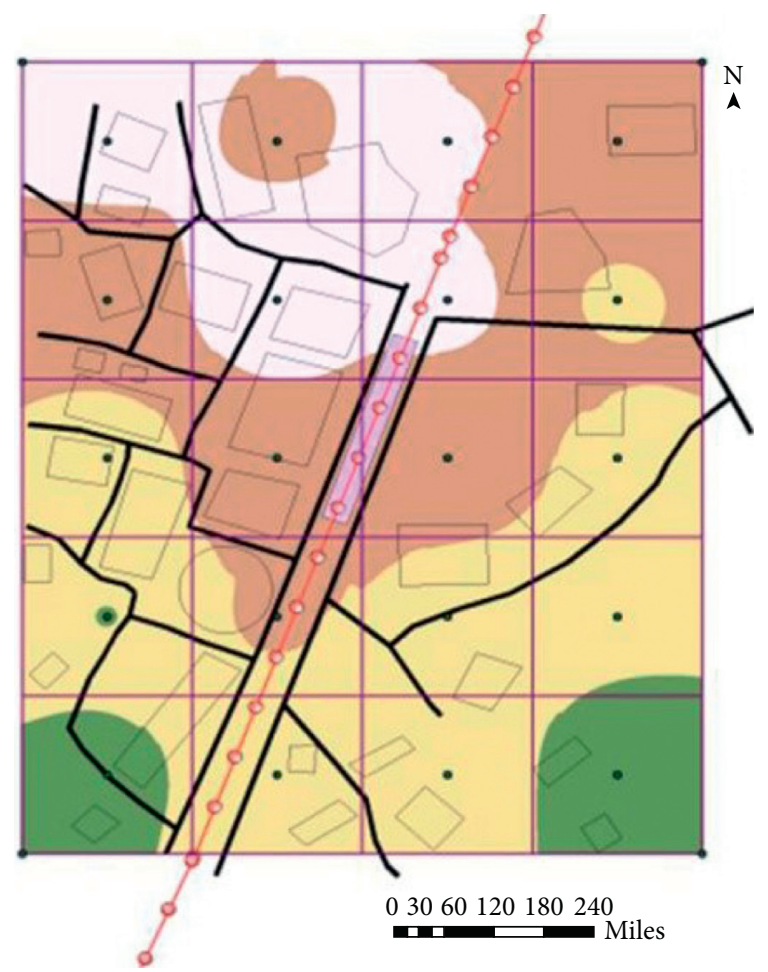

$\mathrm{dB}$ value

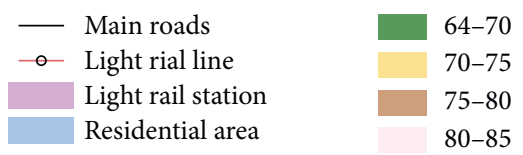

FIgURE 14: Acoustic environment map for the daytime.

environment at 10 p.m. on Friday night showed the largest area with high decibel levels. Figure 10(d) shows that the decibel value of the study area changes greatly and that most residential areas exceed $80 \mathrm{~dB}$ at this time. High-rise residential areas located $80 \mathrm{~m}$ away from the light rail are relatively less affected by noise, and the noise at the area $180 \mathrm{~m}$ away from the light rail station is reduced to $56 \mathrm{~dB}$. Therefore, the residential area along the light rail is more affected by the noise on Friday nights (Figure 13(d)).

4.2. Analysis of Acoustic Environment Map at Daytime and Nighttime. The measured data of each point were used to construct the acoustic environment map, which reflect the actual acoustic environment around the measured point (Tables 1 and 2). After the measured data from the day and night were processed, they were imported into ArcGIS and plotted by inverse distance weighted interpolation. The measured values at 7:00 a.m., 12:00 p.m., and 6:00 p.m. on Monday, Thursday, Friday, and Sunday were then averaged. The average decibel values obtained were then imported into ArcGIS, and inverse distance weighted interpolation was used to obtain Figure 14. Daytime noise levels should not exceed $70 \mathrm{~dB}$; therefore, $70 \mathrm{~dB}$ was used as the threshold. It can be observed from Figure 14 that the lowest decibel value of the residential area along the Yangjiaping light rail is $65 \mathrm{~dB}$. Only few areas had decibel values between 65 and

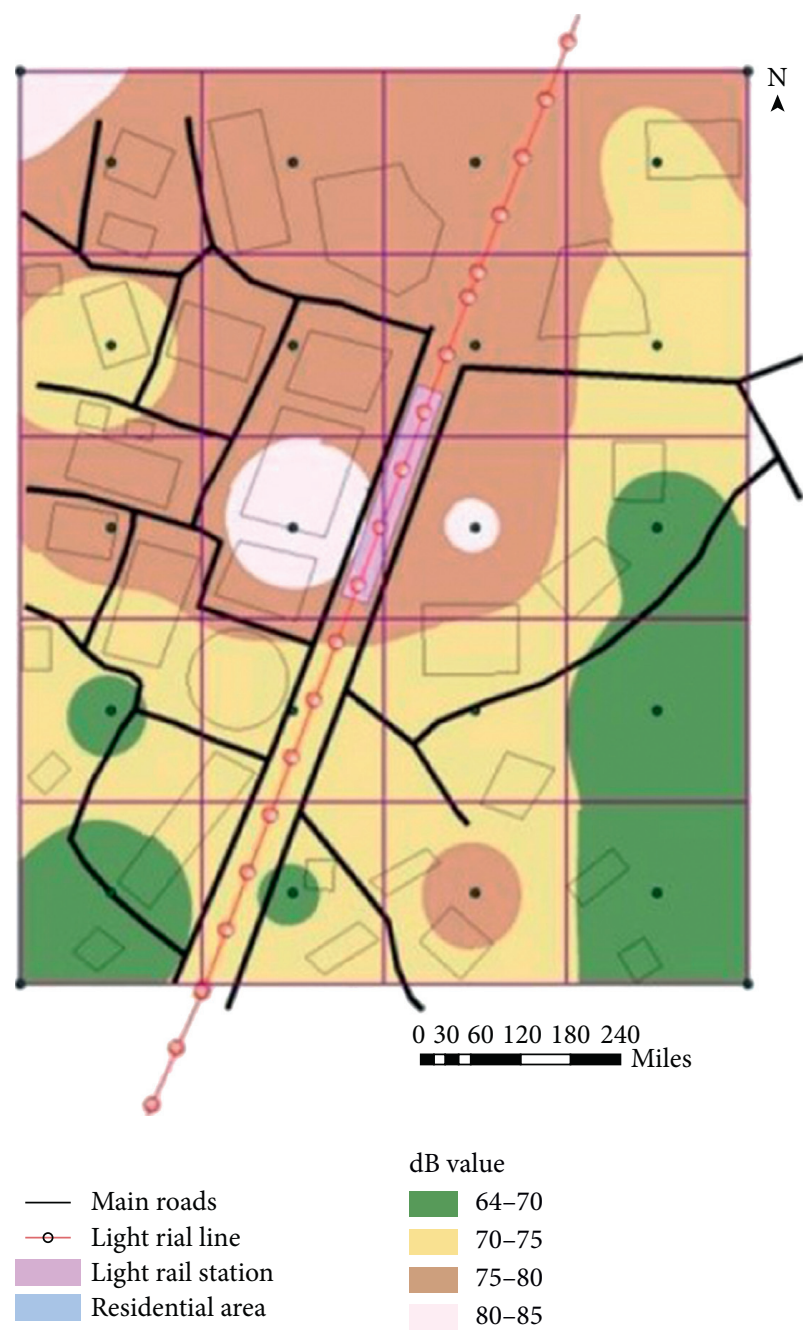

Figure 15: Acoustic environment map for the night.

$70 \mathrm{~dB}$. The proportion of areas that do not meet the minimum requirements of residential noise standards exceeds $90 \%$. In terms of subjective evaluation, the degree of noise pollution suffered by residents in residential areas is very serious and should be given significant attention in terms of implementing effective management strategies to reduce noise pollution.

The data for 10:00 p.m. on Monday, Thursday, Friday, and Sunday were averaged and imported into ArcGIS. Combined with the plan of the study area, the inverse distance weighted interpolation method was used to obtain Figure 15. According to the fourth type of sound environment standard, the decibel value at night should not exceed $50 \mathrm{~dB}$. As can be seen from Figure 15, the lowest decibel value in the study area was $55 \mathrm{~dB}$, indicating that the acoustic environment of residential areas along the Yangjiaping light rail did not reach a comfortable level at night.

\section{Conclusions}

The influence of rail transit noise on the surrounding residential areas is universal, and the influence of noise at night is greater than that during the day. The noise of rail transits 
seriously affects the sleep quality of residents. There is a nonlinear positive correlation between the running speed of rail transits and noise values, and it is related to the distance from the light rail station. The noise attenuates with an increase in the horizontal distance, and the attenuation rate gradually decreases. The noise of rail transit is the same during the day, but the variation in noise on Friday and Monday is higher than that at other times.

By analyzing the acoustic environment of typical residential areas along the Yangjiaping light rail, it can be seen that the noise level in the study area is above $70 \mathrm{~dB}$ during the day and approximately $60 \mathrm{~dB}$ at night. In this acoustic environment, the sound will greatly affect people's rest and comfort of living.

The acoustic environment of residential areas along the light rail should not be ignored. The research data shows that most residential areas in the study area experience higher than the prescribed decibel values and live in an acoustic environment with noise pollution. Therefore, a comfortable and pleasant living environment is needed, and the management of acoustic environment in residential areas along the light rail should be strengthened.

The main influence of the acoustic environment of residential areas along the light rail is the noise generated by social activities and traffic. At different times, due to the change in the activities of people and traffic flow, the acoustic environment changes significantly. The acoustic environment map is an effective method to describe and analyse the noise experienced by residential areas along the light rail, and such a map created by GIS can comprehensively record and analyse the changing characteristics of the acoustic environment of residential areas. Therefore, GIS can be used as an effective means to study the changes in the acoustic environment of certain areas.

\section{Data Availability}

The data used to support the findings of this study are available from the corresponding author upon request.

\section{Conflicts of Interest}

The authors declare that there are no conflicts of interest regarding the publication of paper.

\section{Acknowledgments}

This study was financially supported by the Social Science and Technology Innovation Program for People's Livelihood in Chongqing (cstc2018jscx-msybx0233, cstc2019jscx-lyjsAX0008, cstc2017shms-zdyfX0026, and cstc2019jscxmsxmX0302) and the Science and Technology Research Project of the Chongqing Municipal Education Commission (KJQN201900735).

\section{References}

[1] European Commission, Future Noise Policy-European Commission Green Paper, European Commission, Brussels, Belgium, 1996.
[2] EEA, "Are we moving in the right direction? indicators on transport and environmental integration in the EU: term 2000," Environmental Issue Report No 12, Copenhagen, Denmark, 2000.

[3] B. Mathias, "Single and combined effects of air, road, and rail traffic noise on sleep and recuperation," Sleep, vol. 34, no. 1, pp. 11-23, 2011.

[4] F. Stevens, D. T. Murphy, L. Savioja, and V. Valimaki, "Modeling sparsely reflecting outdoor acoustic scenes using the waveguide web," IEEE/ACM Transactions on Audio, Speech, and Language Processing, vol. 25, no. 8, pp. 1566-1578, 2017.

[5] M. Arana and A. García, "A social survey on the effects of environmental noise on the residents of Pamplona, Spain," Applied Acoustics, vol. 53, no. 4, pp. 245-253, 1998.

[6] M. Brink, "Parameters of well-being and subjective health and their relationship with residential traffic noise exposure-a representative evaluation in Switzerland," Environment International, vol. 37, no. 4, pp. 723-733, 2011.

[7] D. Lai, C. Zhou, J. Huang et al., "Outdoor space quality: a field study in an urban residential community in central China," Energy and Buildings, vol. 68, pp. 713-720, 2012.

[8] R. Shimokura and Y. Soeta, "Characteristics of train noise in above-ground and underground stations with side and island platforms," Journal of Sound and Vibration, vol. 330, no. 8, pp. 1621-1633, 2011.

[9] J. Y. Jeon, P. J. Lee, J. You, and J. Kang, "Perceptual assessment of quality of urban soundscapes with combined noise sources and water sounds," The Journal of the Acoustical Society of America, vol. 127, no. 3, pp. 1357-1366, 2010.

[10] C. M. Harris, Handbook of Acoustical Measurements and Noise Control, McGraw-Hill, New York, NY, USA, 1991.

[11] S. Perron, C. Plante, M. Ragettli, D. Kaiser, S. Goudreau, and A. Smargiassi, "Sleep disturbance from road traffic, railways, airplanes and from total environmental noise levels in montreal," International Journal of Environmental Research and Public Health, vol. 13, no. 8, p. 809, 2016.

[12] M. H. Han, M. K. Joo, and Y. K. Oh, "Residential and acoustic environments perceived by residents of regional cities in korea: a case study of mokpo city," Indoor and Built Environment, vol. 1, no. 19, pp. 102-113, 2010.

[13] G. R. Watts and N. S. Godfrey, "Effects on roadside noise levels of sound absorptive materials in noise barriers," Applied Acoustics, vol. 58, no. 4, pp. 385-402, 1999.

[14] L. Wu and W. Shi, Principles and Algorithms of Geographic Information System, Science Press, Beijing, China, 2003.

[15] http://tech.enorth.com.cn/system/2003/10/28/000658247.shtml.

[16] P. Pereira, R. Grubliauskas, Strukcinskieneb et al., "Effects of urban rail noise level in a residential area," Journal of Vibroengineering, vol. 16, no. 2, pp. 987-996, 2014. 